\title{
Research Involving Biological Material from Forensic Autopsies: Legal and Ethical Issues
}

\author{
Bernice S. Elger ${ }^{a}$ Marie-Claude Hofner ${ }^{b}$ Patrice Mangin ${ }^{a, b}$ \\ University Center of Legal Medicine of Geneva and Lausanne, Universities of a Geneva and ${ }^{\mathrm{b}}$ Lausanne, Switzerland
}

\author{
Key Words \\ Human tissue regulations · Cadaveric material, storage • \\ Biobanks · Forensic autopsy
}

\begin{abstract}
Recommendations and laws do not always contain specific and clear provisions on the use of cadaveric material in research, and even more rarely do they address explicitly the ethical issues related to research on material obtained during forensic autopsy. In this article we analyse existing legal frameworks in Europe by comparing the legal provisions in 2 European Countries which are member states of the Council of Europe, the UK and Switzerland. They were chosen because they have distinct legal frameworks that make comparisons interesting. In addition, the detailed laws of the UK and a specific law project and national ethical recommendations in Switzerland permit us to define more clearly the legal range of options for researchers using cadaveric material obtained during forensic investigations. The Human Tissue Act 2004 in England, Wales and Northern Ireland, its Scottish equivalent with the same title (2006) and the national ethical guidelines in Switzerland all require consent from the deceased person, an appropriate relative or a person with power of attorney for healthcare decisions before cadaveric biological material can be obtained and used for research. However, if the purpose of the autopsy is purely forensic, no such authorisation will be sought to carry out
\end{abstract}

the autopsy and related analyses, which might include genetic testing. In order to be allowed to carry out future research projects, families need to be approached for informed consent, unless the deceased person had left written directives including permission to use his or her tissues for research.

Copyright $\odot 2009$ S. Karger AG, Basel

\section{Introduction}

The use of human biological tissue for research is a controversial subject, especially if tissue samples have originally been taken and stored for other reasons, for example clinical purposes [1]. Collections of biological material obtained for clinical or research purposes are often referred to as 'biobanks' [1]. Such collections are found predominantly in pathology institutions, but exist also in most university hospitals as well as in private institutions. Population biobanks are being established in various countries [2-4]. In order to clarify controversial ethical and legal issues, several countries, including the UK [5], Sweden and Estonia, have passed laws regarding the use of biobanks for research [6], but many countries have not. Some countries, for example Switzerland, have law projects [7]. In several countries, including France, Canada and the USA, national bioethics advisory committees have issued reports and recommendations [8-10].

\section{KARGER}

Fax +4161306 1234

E-Mail karger@karger.ch

www.karger.com
(C) 2009 S. Karger AG, Basel

$1015-2008 / 09 / 0761-0001 \$ 26.00 / 0$

Accessible online at:

www.karger.com/pat
Prof. Bernice S. Elger

Centre universitaire romand de médecine légale

9, av. de Champel

$\mathrm{CH}-1211$ Geneva 4 (Switzerland)

Tel. +41 22379 5589, Fax +41 22789 2417, E-Mail Bernice.Elger@hcuge.ch 
International guidance is provided by the Council of Europe in its recent recommendation on research on biological materials of human origin [11]. Most guidelines and laws apply to collections of human biological material in general and some include particular, additional, regulations for population biobanks. These additional measures are mostly reinforced oversight mechanisms such as audits and/or registers $[7,11]$.

These European recommendations and laws address ethical issues related to material obtained from donors in general. They do not always contain specific and clear provisions on the research use of cadaveric material. Even more rarely do they address explicitly the ethical issues related to research on biological material obtained during forensic autopsy.

Whereas the legal and ethical problems of research involving material stored by non-forensic pathologists are being discussed in a growing number of publications [5, 12], the implications of recent legal and policy developments on research in the forensic context has only very rarely been addressed [13]. The aim of this article is to fill this gap. It will pay special attention to regulatory issues concerning research involving cadaveric tissue obtained during forensic investigation.

The article has 3 parts. First, we will provide an overview of the general ethical and legal principles that guide research involving biobanks in Europe, which follow recent recommendations from the Council of Europe and legislation, especially from the UK and Switzerland. We will focus on issues that are relevant for research by forensic and other pathologists.

Second, we will analyse in more detail the existing legal provisions in 2 European countries that are members of the Council of Europe, the UK and Switzerland. They were chosen because they have distinct legal frameworks that make comparisons interesting. In addition, the detailed laws of the UK and a specific law project and national ethical recommendations in Switzerland permit us to define more clearly the legal range of options for researchers using cadaveric material obtained during forensic investigations.

We will identify and examine legal provisions addressing explicitly research involving cadaveric tissue obtained during forensic investigation. Where such provisions are lacking, we will discuss whether and how more general provisions for research involving other kinds of human tissue apply to the forensic context.

Third, we will not only examine the theoretical legal framework, but also consider the specific practical and ethical problems faced by researchers, pathologists and research ethics committees (RECs) that arise in the forensic context under these specific legal frameworks.

The aim of this discussion of existing ethical guidelines, ethical arguments and practical problems is to help forensic pathologists choose the most acceptable approach when planning prospective research on cadaveric material obtained during forensic autopsies.

\section{Research Involving Biobanks in Europe: General Ethical and Legal Principles}

The recent public attention to the ethical use of human biological material $[14,15]$ has caused changes that are important for the way in which pathologists in general and forensic pathologists in particular store and use human biological material. These changes are especially important in the area of obtaining consent.

\section{Consent to Research Involving Tissues}

The Council of Europe has affirmed repeatedly that if biological material is obtained for research, 'consent or authorisation to obtain such materials should be as specific as possible with regard to any foreseen research uses' $[11,16]$. Biobanks are particularly affected by the issue of consent to secondary uses. Tissue collections established by pathologists working in a clinical and/or forensic context, and biobanks obtained primarily for a defined type of research are relevant examples concerning the council's statement about secondary uses. All these different types of tissue collections might be useful for future research, including types of research that were unknown at the time when the material was collected.

Briefly, the legal and ethical principles concerning research on material from living or dead donors require investigators to routinely obtain separate consent for research, either from donors or - if the donor is deceased - from their family, and to make an effort to obtain both specific consent for defined research projects and broader consent for future studies.

\section{Waivers of Consent}

It is rare for exceptions to be made that authorise research without the relevant consent. Legislations do, in general, provide for certain explicit exceptions. For example, in the UK these include storage and use of tissue that has been removed from a living person for education and training [17]. This is not the case in Switzerland, where national guidelines require similar consent for education and training as for research [18]. 
The Council of Europe permits an exception for consent to research involving so-called 'residual material'. Article 22 of the recommendations states that if the proposed use of identifiable [residual] biological materials in a research project is not within the scope of prior consent, if any, given by the person concerned, reasonable efforts should be made to contact the person in order to obtain consent to the proposed use'. If, in spite of reasonable efforts, it is not possible to contact the person concerned, 'these biological materials should only be used in the research project subject to independent evaluation of the fulfilment of the following conditions: (a) the research addresses an important scientific interest; (b) the aims of the research could not reasonably be achieved using biological materials for which consent can be obtained; and (c) there is no evidence that the person concerned has expressly opposed such research use'. However, the Council of Europe makes clear that these exceptions for residual biological materials 'removed for purposes other than storage for research' should not become routine practice. Indeed, article 12 clearly states: 'Whenever possible, information should be given and consent or authorisation [for research] requested before biological materials are removed.'

The recommendations from the Council of Europe, as well as legislation in a number of European countries, contain another notable exception. Secondary research use without consent is permitted on biological material obtained with consent for a primary purpose, if the material is irreversibly anonymised, also called 'unlinked anonymised'. Irreversible anonymisation means that it is not possible to link the tissue and associated information to data permitting the identification of the tissue donor. Legislation in some countries extends this exception to reversibly a nonymised, also called 'linked anonymised', tissue and information. In this case, identification of the donor is possible via a code, but the users of the material do not have access to this code. In line with this concept, in the USA, consent is not required if non-anonymised material contained in a biobank is given out to researchers in a way that does not permit them to identify the donor $[19$, 20]. In the UK, this exception was introduced as an amendment to the Human Tissue Act 2004 during the bill's passage through Parliament, after researchers expressed their fears that the new Act would severely restrict research. This amendment permits the use and storage of tissue without consent under the condition that the tissue is anonymised and that the research study has been approved by a research ethics committee (s1, 7-9 of the Act [17]).

Switzerland is currently discussing a new law project on human subject research which includes research on

Research Involving Biological Material

from Forensic Autopsies tissue. This Swiss federal law project provides an interesting consent waiver, which is limited to cadaveric tissue, and foresees the possibility for research on cadaveric tissue without consent of the deceased persons or their relatives under particular circumstances. According to the Swiss law project, it is permissible to use biological material obtained from an autopsy for research without consent [7] if the samples are anonymised, if the quantity of material used is minimal and if there is no document attesting the refusal of the deceased person. All conditions need to be fulfilled simultaneously. Minimal quantity is defined in the official commentary to the law [21] as meaning any quantity the lack of which does not represent an additional harm to the corpse. It must therefore be a very small quantity. Obtaining any macroscopic part or entire organ or doing any other type of research involving a deceased person or body parts is considered an additional harm. This type of research must be covered by the consent obtained from the individual before death or further consent must be obtained from the next-of-kin or a therapeutic representative chosen by the deceased. The next-of-kin according to Swiss jurisdiction is the person who had the closest relationship with the deceased person immediately before this person died. In the UK, the nextof-kin are ranked, ranging from spouse or partner over parent or child to longstanding friends, and in Switzerland a change of the civil law is under discussion which might introduce a similar ranking. At present, this ranking has already been introduced by application law (ordonnance) to the Swiss transplantation law from 2007.

It remains to be seen whether and to what extent the different consent waivers will be used in the future, especially for long-term collection and storage of tissue for use in large tissue banks. As the next section will show, it is not clear whether and under which conditions waivers would be accepted by RECs. For most types of tissue banks 'obtaining consent is likely to be regarded best practice for long-term storage and use' [17].

\section{Consent and the Role of Research Ethics Committees}

It should also be noted that a considerable number of details defining 'appropriate' consent will be left to the judgement of individual RECs. Legal provisions define a rather broad framework, and they do not offer special guidance to RECs on how to judge specific details of a given research protocol. Indeed, RECs are bound by the legal provisions, but could add even stricter ethical requirements before approving a particular study.

It is well known that research involving biological samples stirs controversy especially if genetic testing is 
part of the project. A few years ago, researchers in the UK encountered variations in the ethical standards of local RECs concerning a multi-centre study involving genetic testing of samples obtained from people who died from sudden arrythmic death syndrome [22]. Meanwhile, a new ethics approval mechanism has been created for tissue banks in the UK [5]. It offers the possibility to tissue banks to obtain a sort of general approval that includes operating the bank, obtaining samples according to an approved protocol, and giving out tissue to researchers. For research that is within the scope of the biobank's approved range of projects, researchers do not need to request ethics approval themselves. This simplified approval mechanism could be useful if special collections of tissue were established by forensic or other pathologists, but would not automatically apply to research involving consecutive single autopsy cases related to sudden death. These would need regular REC approval, especially if genetic testing is involved. Researchers have complained that RECs apply unnecessarily strict rules. The risk exists that RECs refuse protocols mainly as an overreaction to the highly emotionalized debate about the use of tissue in order to 'be on the safe side' $[23,24]$.

\section{Broad versus Narrow Consent}

The scope of consent is a notorious reason for controversy in the ethical and legal debate about biobanks. In both the UK and in Switzerland, it is best practice to ask for specific informed consent if a particular research project is already defined. The typical problem of research involving stored biological material is that the details of future research projects are not yet known. However, it is difficult if not impossible to obtain new informed consent for each new research project. Should broad consent that does not imply detailed information about future research projects be valid for stored material? While professional organisations such as the European Society of Human Genetics [25] or the College of American Pathologists [26] and national guidelines from several countries $[18,19,27]$ claim that broad forms of consent are acceptable, there is strong resistance to abandoning the classic type of specific informed consent, especially in the USA [19].

In the UK, broad consent is used in the UK biobank project that has been enrolling participants since February $2007[28,29]$. Broad consent for research is allowed to some extent in the UK by its new legal provisions and it is implied that such consent may be long lasting [5]. Broad consent is also permissible according to ethical recommendations. Indeed, the UK Medical Research Council
(MRC) approves it under certain conditions. The MRC guidelines [30] combine elements of broad and specific consent within a 2-layered consent. Concerning cadaveric material, the wishes of the deceased person have to be taken into account in the first place. According to article 11.1, 'before removing and retaining human material for research at a post-mortem examination, all reasonable steps must be taken to ascertain that the deceased would not have objected (for example, for religious reasons)' [30]. If no reason exists to believe that the deceased person has objected, informed consent from the next-ofkin must be obtained. Consent to storage has to be as specific as possible. The article continues: 'The person asked to give consent should be given clear information about what tissue/organ will be retained, who will be custodian, how long the sample will be kept, what types of research it may be used for and how it will be disposed of when no longer required.' Although the MRC opposes blanket consent, which is described as 'unconditional' consent to 'all biological or medical research', it allows for some form of broad consent in form of a '2-part' consent [p. 15 in 30]. First, specific consent is given to an already defined research project and then a broader consent to other future studies is added. The MRC is aware that future research is partly or totally 'unforeseen'. This contradicts the idea of providing detailed information at the beginning. The guidelines seem to permit future research to be carried out without new specific consent, if the project is approved by an ethics committee and if the results will not have direct clinical implications for the deceased individuals or their family members.

In article 11.1 the MRC recommends specific precautions if biological material will be used for genetic testing. While in the case of removal of samples from a deceased person there is clearly no possibility of physically harming the person from whom the material is obtained, 'some research results (e.g. from genetic studies) may have implications for the surviving family members. The potential implications for relatives of any research to be done using linked [identifiable] samples must be discussed, and they [relatives] must be given the opportunity to learn about any research results that might impact on their interests' [30]. Among the proposed safeguards is the possibility to withdraw consent, which is mentioned in the MRC's example of a consent form [p. 33 in 30]. The consent form contains the wording: 'I agree ... that I am free to withdraw my approval for use of the sample at any time without giving a reason.' As explained by the MRC, withdrawal of consent is of ethical importance with respect to cadaveric material since the consent of family 
members 'is being sought at a particularly stressful time'. Hence, 'relatives should wherever possible, be given time to reflect before making their decision, and it is particularly important that written information is provided for later reference. Contact details of the research team must be provided in case relatives have further questions or change their minds later' [30].

Finally, it is of interest to know that the main request from patients and families is to be informed about organs and tissue being retained for research. The majority of them find broad and long-lasting consent acceptable [15, 31, 32].

In Switzerland, for the time being the guidelines of the Swiss Academy of Medical Sciences (SAMS) authorise broad consent. Article 4.3 of these guidelines states: 'Consent can generally also cover the further use of the samples and data for future research projects (general consent).' This broad consent is appropriate for all types of research which do not involve special risks for donors and in which reversibly or irreversibly anonymised samples are used. 'The donor must however expressly give his consent to a research project' if 'this envisages research with non-anonymised samples' [18]. In the case of cadaveric biological material, it is difficult to imagine 'special risks for donors', unless one takes into account risks related to the violation of confidentiality. Indeed, the dignity of deceased donors might be affected if they are found to test positive for stigmatising diseases, such as HIV, other sexually transmitted diseases or perhaps some genetic disorders. Ethical problems of research involving genetic testing of cadaveric material are related less to the risks to the deceased individual than they are to concern for the consequences for family members. These people have a right to know and a right not to know. Both can be respected if broad consent to research with autopsy material is obtained from close relatives.

Although the Swiss guidelines allow for restriction of the use of the tissue to one specific field of research [18], it is advisable for researchers to keep the consent as broad as possible and to include consent to genetic testing. Several RECs have so far accepted forms of broad consent for biobanks in Switzerland: examples are the tumour bank in Berne [33] and the Swiss national paediatric tumour bank in Zurich [34]. In both biobanks genetic testing is permitted. The information leaflet provided states that sample donors have the right to refuse feedback about the research results, thereby respecting both their right to know and not to know. If research participants do not refuse feedback, the biobanks will inform the donor's treating physician of any results that are important for the health of the person who provided the samples.

Swiss guidelines, like most guidelines that favour broad consent, admit that those who consented should have the right to opt out of future projects $[18,25,27$, 30].

\section{Research on Cadaveric Material Obtained during Forensic Investigation}

\section{Recommendations from the Council of Europe}

In the following we examine legal provisions that apply in the forensic context. Where specific legislation is lacking, we refer to more general provisions and interpret their meaning for the forensic pathologist. The specificity of the forensic context is that autopsies and storage of material are carried out without family consent at the request of a judicial authority. Forensic pathologists are not routinely in contact with the family of the deceased person. Indeed, forensic pathologists remove, store and analyse cadaveric human biological material at the request of a judicial authority, such as a coroner [35] in England, Wales and Northern Ireland $[13,36]$, a procurator fiscal in Scotland $[13,37]$ or the examining magistrate in Switzerland. The stored material might be useful for research after the legal procedure - in general, a death investigation - has come to an end.

The recommendations from the Council of Europe do not contain an explicit section on research on cadaveric material obtained in a forensic context. Therefore, forensic pathologists must refer to recommendations on the use of cadaveric material in general. The exact meaning of this section, however, is open to interpretation. Article 13 of the recommendations states only: 'Biological materials should not be removed from the body of a deceased person for research activities without appropriate consent or authorisation.' It is not further defined which consent or authorisation procedures are appropriate, except that any of these procedures will be invalidated if the deceased person is known to have objected to research activities. In this case, biological materials should not be 'removed or supplied' for any type of research [11].

\section{UK and Swiss Legal Frameworks concerning Forensic Biological Material}

Since special guidance from the Council of Europe is lacking, it is useful to also examine legislation in countries that are members of the Council of Europe. Recent new legal provisions in some countries, such as the $\mathrm{Hu}-$ 
man Tissue Act 2004 in the UK, might help to clarify the limits within which forensic pathologists will be allowed to carry out research on cadaveric tissue. The UK has recently enacted 2 tissue acts, one applying to England, Wales and Northern Ireland and the other to Scotland. If a person in the UK dies from suspicious, unnatural or unknown causes, the judicial and forensic evaluation takes place under the authority of a coroner (in England, Wales and Northern Ireland) or a procurator fiscal (Scotland). Since Scotland and the rest of the UK have recently enacted different new tissue legislation, forensic autopsies do not follow exactly the same rules. This could create problems for national research endeavours and other types of collaboration $[13,38]$. In the past, forensic pathologists were obliged to store any material that might, according to their knowledge, be useful to determine the cause of death. The length of storage was determined by the coroner for each case. It was not clear whether the coroner was authorised to request ongoing storage after the end of the legal investigation. In addition, coroners were under no obligation to inform relatives of the deceased person about the storage of the tissue. The new amended rules from 2005 [36] try to fill the gap and define further obligations. First, UK pathologists outside Scotland must provide detailed information to the coroner about the stored material. Second, the next-of-kin has to be able to decide between donation for research or destruction of the material. The next-of-kin of an adult is defined by article 3.6c in the Human Tissue Act [35] as the 'person who stood in a qualifying relationship to him immediately before he died'. Qualifying relationships are defined in section 3.6c and, according to the Act, should be ranked in a given order ranging from spouse or partner, parent or child, brother or sister to a friend of longstanding (article 27.4). When the authority of a coroner ends at the conclusion of the investigation, material can only continue to be stored with appropriate consent, for example from donors or relatives, as defined by the $\mathrm{Hu}-$ man Tissue Act [35].

The situation is different in Scotland, at least concerning small quantities of material. Entire organs can be stored only with the consent of the appropriate relatives once the legal investigation has come to an end. However, tissue blocks and slides can be lawfully stored after the procurator fiscal has closed the investigation. The use of these tissue blocks and slides is restricted to diagnostic review and audit. Any other use, for example for research or education, is authorised only with the appropriate consent [13].
Switzerland is composed of 26 cantons, and distinct cantonal laws exist in each of them. At present, in some regions, cantonal law restricts the use of forensic tissue beyond the requirements found in national or federal recommendations. In order not to overly complicate the comparison, we will limit the analysis of the Swiss legal basis to national recommendations and forthcoming federal law which will, if enacted, in principle overrule cantonal dispositions. Since the Swiss law on research involving human subjects and human tissue has not yet come into force, presently the use of human biological material for research is guided by national recommendations from the SAMS [18], which are of legal value according to a decision from the federal supreme court. The SAMS guidelines refer specifically to the use of cadaveric material obtained during forensic investigation (in part III). This part discusses tissue collections established by forensic pathologists: 'Parts of cadavers that were obtained and preserved in the course of investigations carried out according to criminal law or by other authorities may be kept in special collections after expiry of the storage time required for legal reasons and with the consent of the authorities ordering these measures, provided there are scientific reasons and reasons of education and general interest for doing so. In this respect, any objections to storage of the preparations on the part of close relatives must be taken into account.'

Since part III relates to 'special collections' only, forensic pathologists should also be aware of a second part of the guidelines which concerns the prospective use of material from deceased persons in general: 'If material is removed from a deceased person (e.g. in the course of an autopsy), that person's prior consent to the storage and further use of this material for the purposes of research is necessary (patient's prior instructions). If the deceased person had not given consent, the closest relatives may give their consent, provided this is not in contradiction of the deceased's wishes expressed or presumed during his lifetime' (part 4.5) [18].

Whereas in the second quotation consent of relatives to research is obligatory, although overridden by any presumed refusal of the deceased person, the quotation relating to forensic medicine (part III) is somewhat more ambiguous since it does not explicitly use the term 'consent', but refers only to 'any objections' on the part of close relatives. Part III could be interpreted to mean a form of presumed consent, putting the burden of manifesting objection on relatives. This could imply that forensic pathologists are under no obligation to contact relatives in all cases, as long as they have obtained permission from 
the judicial authorities who authorised tissue removal in the first place. However, the provisions described in part III seem to provide mainly an authorisation for storage and not for specific research projects. For specific research projects, the stricter requirements of part 4.5 are likely to be regarded as best practice and will probably need to be followed.

The federal law project provides the possibility for research on cadaveric tissue without consent of the deceased persons or their relatives under the circumstances discussed above (anonymity, small quantity, no objection of the donor).

\section{Putting Law into Practice: Legal and Ethical Issues concerning Research with Human Material from Forensic Autopsies}

As the preceding parts show, the legal context in both countries concerning research involving forensic biological material is not very detailed and leaves a number of questions open. In the following part we will discuss in more detail the main ethical, legal and practical issues a forensic pathologist has to face regarding this research. For each issue it is important to put the legal texts into the broader ethical context.

The local legal basis, as described above, provides a framework that must not be transgressed. Within this legal framework, a range of options exist. These options have to be carefully evaluated with respect to details that make them more or less ethically acceptable. Existing professional and national ethical guidelines, as well as the balancing of ethical principles and ethical arguments, help to identify the most appropriate approach. In the following we will discuss different options to the forensic pathologist concerning consent to storage and research.

\section{Consent to the Storage of Biological Material:}

Recommendations That Apply to Forensic

Pathologists Similarly as to Other Researchers

Forensic pathologists, like their colleagues outside forensics, cannot ignore the changes due to recent public attention which has brought about new legal frameworks and ethical recommendations concerning the use of human biological material. New regulations concern the storage of human biological material. As the above summary of new laws and recommendations has shown, past practice for storing material beyond the end of forensic investigations is no longer permitted in most parts of Switzerland and the UK (except Scotland where the stor- age of small quantities of material for clinical purposes is allowed [13]). Since the material is scientifically valuable, forensic pathologists have an ethical obligation to plan for legally acceptable forms of storage ahead of time.

It is important for pathologists and forensic pathologists to be aware of the more general ethical and legal issues, as well as recent specific guidelines and laws. Consent to storage and a specific research project should be distinguished from broad consent to future studies. Different forms of valid consent to future research exist and it is useful not to unnecessarily restrict further uses of the biological material by a type of consent that is narrower than legally or ethically required.

Therefore, for forensic pathologist it is advised to use always a '2-part' consent from relatives of autopsied victims, as has been explained above. In addition to the specific consent to the defined project, broad consent to future research projects should be obtained. This broad consent is ethically acceptable not only for research in institutes of non-forensic pathology, but also in the forensic context. It does not represent an abuse of the confidence of those who consent, if all future research projects need approval of a research ethics committee, as recommended by the MRC and is the case, for example, in Geneva. The REC will judge if the broad consent is sufficient in light of the risks involved in a future individual research project on tissues. For some particularly sensitive projects involving genetic testing, the REC might require specific consent and oblige researchers to contact family members for new consent.

In addition, forensic pathologists should grant those who consented the right to opt out of future projects, as included in most guidelines that favour broad consent $[18,25,27,30]$.

Research without consent on samples stemming from forensic autopsies will be possible if the text of the Swiss law project is maintained and the law comes into force in 3 or 4 years. As stated above, according to the permissive approach defined by the present law project, cadaveric tissue within, but also outside, the forensic context can be used without consent of the deceased persons or their relatives if 3 conditions are fulfilled simultaneously: the samples are anonymised; the quantity of material used is minimal, and there is no document attesting the refusal of the deceased person [7]. This would permit a number of types of research at the histological or microscopic level and relieve the forensic pathologist of the burden of obtaining consent from grieving relatives. It is, however, not clear whether genetic testing without consent is allowed within the scope of this law project. Since forensic 
pathologists examine typically cases of sudden deaths where genetic testing might be indicated $[39,40]$, they will still have to rely on consent from relatives for research even if the law project comes into force. In addition, even if the law did not require consent from the deceased persons or their relatives, this does not remove the need for REC approval of research projects involving genetic testing. The REC will evaluate whether the genetic tests might have any consequences for the health or life of the deceased person's family members. In this case, feedback of research results to the relatives could be indicated $[41,42]$. In addition, research on completely anonymised samples could be judged inappropriate in this situation and the REC could require that consent of family members should be sought.

\section{Specifics to the Forensic Context and Ethically \\ Relevant Practical Problems}

Storage of Particular Types of Forensic Biological

Material

As discussed above, presently the SAMS guidelines contain a somewhat ambiguous statement indicating that the storage of samples obtained during forensic autopsies - albeit probably not all types of research - could be authorised with some form of presumed consent (part III [18]). This exception is presently explicitly limited to forensic collections and does not apply for other types of biological material. The exact characteristics of forensic tissue collections that fall under this particular exception are not defined, other than the condition that scientific reasons, reasons of education or a general interest must exist.

Permission from Judicial Authorities

It is important to routinely obtain appropriate permission from judicial authorities for further storage and reutilisation for research of the biological material, especially since the administrative burden is minimal and the request is in most cases not more than a formality. Indeed, as the MRC in the UK points out, the coroner (or procurator fiscal in Scotland) can prohibit research, even if consent has been obtained from a relative. 'Therefore the coroner or procurator fiscal must be consulted before tissue is retained for research' [section 11.2 in 30].

On the other hand, the MRC states that the judicial authority (coroner, judge, etc.) 'cannot authorise the retention of tissue for research', even following autopsies required by law because consent of the deceased person or his/her relatives is required. The legally valid and ethically most appropriate practice is, therefore, to envision routinely consent of relatives to storage and to future research during or around the end of the forensic investigation when it is still possible to make contact with the relatives through the judicial authority.

However, obtaining consent from family members implies practical problems and many of these problems are ethically relevant. When planning consent procedures, it is important to pay attention to the way in which consent is obtained (by whom and when) and to the type of consent used.

\section{Practical and Ethical Problems of Routine Consent}

in Forensic Pathology

The Human Tissue Act 2004 in England, Wales and Northern Ireland, its Scottish counterpart (2006) and the national ethical guidelines in Switzerland require consent either of the deceased person or of an appropriate relative or therapeutic representative, before cadaveric biological material can be obtained and used for research (although the Scottish Act uses the term 'authorisation' instead of consent, the concept seems to be the same [5]).

However, if the purpose of the autopsy is purely forensic, no authorisation will be obtained from the family to carry out the autopsy and related analyses, which might include genetic testing. Families must be approached for informed consent to future research projects unless the deceased person had left written directives including permission to use his or her tissue for research. At present, such a living will is a rare occurrence.

The definition of the appropriate next-of-kin varies in different jurisdictions and is not the same in the UK and Switzerland, as shown above. Obtaining next-of-kin consent for research use of tissue obtained during forensic autopsy is ethically and practically daunting. The forensic pathologist has access to the family only through the judicial authority, and only the coroner or examining magistrate in charge of the case can authorise such contact and provide the addresses. In some cases of sudden, unexpected deaths outside hospital, it might not be easy or possible to identify relatives, especially if the death has occurred at great distance from the place where the deceased person lived.

It is open to debate who should contact the next-of-kin in order to obtain consent for research involving tissue obtained after forensic autopsies [43]. The person to make contact could be from the office of the judicial authority in charge of the case, the forensic pathologist, the researcher (who could be a geneticist) or a third party. Who carries out the task has an ethical dimension because it 
could affect the quality of the information provided to the person who has to give consent and it might influence significantly the rate of agreement to research. Physicians trained in forensic medicine have, in general, sufficient experience to interact with relatives of a deceased person. However, the person who obtains informed consent should also have sufficient time and understanding of the research project to discuss it with the relatives. If the contacting forensic physician/pathologist is not actively taking part in the research project, then it is unlikely that this would be the case.

Another point to consider is that consent to research must be both freely given and informed. Since the forensic autopsy is ordered by a judicial authority, the relative approached might feel under pressure to consent to research, especially if the family is contacted by a person involved in the legal procedure and the forensic investigation. In this context one must also consider the possibility that consent is refused if the next-of-kin who has to provide consent was involved in the death, suspects a family member to be involved whom he or she wants to protect, or feels guilty for some (even irrational) reason. In these cases the next-of-kin might wish to make sure that no further investigation is possible and ask for destruction of all material.

On the other hand, geneticists, other researchers or third parties are not familiar with legal issues related to forensic autopsies and lack experience with bereaved relatives in this context.

A more general problem is when to contact the family. A study in the UK showed [22] that several families were too grief-stricken to agree to their own participation in a study involving cardiac assessment. It is unclear whether they would consent to research involving tissue from the deceased person. In this context, the principal questions to be answered are whether it is justified to assume that family members will be able to provide free and informed consent in emotionally difficult situations such as the death of a close relative, and whether it is ethically appropriate to approach families systematically. However, if the benefit for other patients or for society is important, as is the case for the procurement of organs for transplantation or for certain types of research with severely ill incapacitated patients, ethics committees have considered in the past that it is justified to approach grief-stricken families for consent. Sufficient reasons exist to indicate that it is ethically appropriate to ask family members for consent to future research use of biological material taken from a deceased relative. Unlike in the situation of a retrieval of organs for transplantation, in the forensic set- ting families can be approached several weeks or months after the death of their relative for those biological materials that have been stored legally until then because storage was part of the forensic investigation. In light of the scientific value of the material, the stress imposed on families at a greater distance in time from their acute grief does not seem disproportional. In addition, some families could even be relieved that some tissue or DNA of their deceased relative could be of benefit and help to further scientific knowledge and public health.

\section{Conclusions}

Although the legal frameworks regulating prospective research on autopsy samples in the UK and in Switzerland are presently different, some basic requirements are alike. In addition, national guidelines from both countries contain many analogous argumentations and conclusions. As a consequence, the recommended approach for forensic pathologists is similar in the UK and Switzerland. Indeed, the aim is not only to stay within the limits of the law, but also to choose the most ethical approach. The main elements of this approach are to routinely obtain: (1) authorisation from competent judicial authorities for storage and research use, and (2) broad consent from the appropriate next-of-kin, unless consent to storage and research has already been provided by the deceased person prior to death. Relatives should be approached, if possible, at a time after their period of acute grief, and the consent form should explicitly mention genetic testing. If a specific research project is defined at the time of the consent, in addition to broad consent to future research projects, specific informed consent to this project is required. REC approval should be obtained for future research projects on samples that have been stored with broad consent from relatives, and those who provide consent should be informed about their right to withdraw consent in the future.

\section{Acknowledgement}

Funding was provided by the Swiss National Science Fundation and the Geneva International Academic Network. 


\section{References}

$>1$ Riegman PH, Dinjens WN, Oosterhuis JW: Biobanking for interdisciplinary clinical research. Pathobiology 2007;74:239-244.

$>2$ Schmitz G, Aslanidis C, Liebisch G, Orso E: The Danubian Biobank project. Stud Health Technol Inform 2008;134:143-159.

$\checkmark 3$ Fan CT, Lin JC, Lee CH: Taiwan Biobank: a project aiming to aid Taiwan's transition into a biomedical island. Pharmacogenomics 2008;9:235-246.

4 Asslaber M, Abuja PM, Stark K, Eder J, Gottweis $\mathrm{H}$, Trauner M, Samonigg H, Mischinger HJ, Schippinger W, Berghold A, Denk H, Zatloukal K: The Genome Austria Tissue Bank (GATiB). Pathobiology 2007;74:251258.

5 Clark BJ: Tissue banking in a regulated environment: does this help the patient? 1. Legislation, regulation and ethics in the UK. Pathobiology 2007;74:218-222.

$\checkmark 6$ Gibbons SM, Helgason HH, Kaye J, Nomper A, Wendel L: Lessons from European population genetic databases: comparing the law in Estonia, Iceland, Sweden and the United Kingdom. Eur J Health Law 2005;12:103-133.

7 Law Project: Loi fédérale relative à la recherche sur l'être humain (loi relative à la recherche sur l'être humain, LRH). 2006. http:// w w w. ad min.ch/ch/f/g g/pc/documents/1266/HFG_f.pdf (accessed November 2007).

8 NBAC: Research Involving Human Biological Materials: Ethical Issues and Policy Guidance, Report and Recommendations. Rockville, National Bioethics Advisory Commission, 1999, vol 1.

9 Comité consultatif national d'ethique pour les sciences de la vie et de la santé: Avis No. 77: problèmes éthiques posés par les collections de matériel biologique et les données d'information associées: 'biobanques' 'biothèques'. 2003: http://www.ccne-ethique.fr/ docs/fr/avis077.pdf (accessed September 2008).

10 Commission de l'éthique de la science et de la technologie: Les enjeux éthiques des banques d'information génétique: pour un encadrement démocratique et responsable. 2003. http://www.ethique.gouv.qc.ca/IMG/ pdf/AvisBanquesGen.pdf (accessed September 2008).

11 Council of Europe: Recommendation $\operatorname{Rec}(2006) 4$ of the Committee of Ministers to member states on research on biological materials of human origin. 2006. https://wcd. coe.int/ViewDoc.jsp?id=977859\&BackColorInternet $=9999 \mathrm{CC} \&$ BackColorIntranet $=$ FFBB55\&BackColorLogged=FFAC75 (ac cessed June 2007).

12 van Diest PJ, Lopes Cardoso NW, Niesing J: Cadaveric tissue donation: a pathologist's perspective. J Med Ethics 2003;29:135-136.

13 Underwood JC: The impact on histopathology practice of new human tissue legislation in the UK. Histopathology 2006;49:221-228.
14 Bennett JR: The organ retention furore: the need for consent. Clin Med 2001;1:167-171.

15 Borisch B: Tissue banking in a regulated environment: does this help the patient? 2. Patient views and expectations (including the Europa Donna Forum UK position). Pathobiology 2007;74:223-226.

16 Council of Europe: Additional protocol to the convention on human rights and biomedicine, concerning biomedical research. 2005. http://conventions.coe.int/treaty/en/ Treaties/Html/195.htm (accessed December 2007).

17 McHale J, Habiba M, Dixon-Woods M, Cavers D, Heney D, Pritchard-Jones K: Consent for childhood cancer tissue banking in the UK: the effect of the Human Tissue Act 2004 Lancet Oncol 2007;8:266-272.

18 Swiss Academy of Medical Sciences: Biobanks: obtainment, preservation and utilisation of human biological material: medicalethical guidelines and recommendations. 2006. http://www.samw.ch/docs/Richtlinien/e_RL_Biobanken.pdf (accessed September 2008).

19 Elger BS, Caplan AL: Consent and anonymization in research involving biobanks: differing terms and norms present serious barriers to an international framework. EMBO Rep 2006;7:661-666.

20 Guidance on research involving coded private information or biological specimens. Rockville, Office for Human Research Protections, 2004.

21 Département Fédéral de l'Intérieur, Berne: Explications: La loi fédérale relative à la recherche sur l'être humain (loi relative à la recherche sur l'être humain, LRH): rapport explicatif concernant l'avant-projet. Département Fédéral de l'Intérieur, 2006.

22 Behr E, Wood DA, Wright M, Syrris P, Sheppard MN, Casey A, Davies MJ, McKenna W: Cardiological assessment of first-degree relatives in sudden arrhythmic death syndrome. Lancet 2003;362:1457-1459.

23 Khong TY, Tanner AR: Foetal and neonatal autopsy rates and use of tissue for research: the influence of 'organ retention' controversy and new consent process. J Paediatr Child Health 2006;42:366-369.

24 Auray-Blais C, Patenaude J: A biobank management model applicable to biomedical research. BMC Med Ethics 2006;7:E4.

25 European Society of Human Genetics: Data storage and DNA banking for biomedical research: technical, social and ethical issues. Eur J Hum Genet 2003;11(suppl 2):S8-S10.

-26 Grizzle W, Grody WW, Noll WW, Sobel ME, Stass SA, Trainer T, Travers H, Weedn V, Woodruff K: Recommended policies for uses of human tissue in research, education, and quality control: Ad Hoc Committee on Stored Tissue, College of American Pathologists. Arch Pathol Lab Med 1999;123:296300 .
27 Nationaler Ethikrat: Biobanken für die Forschung: Stellungnahme. 2004. http:// www.ethikrat.org/themen/pdf/Stellungnahme_Biobanken.pdf (accessed September 2008).

28 UK Biobank: Consent form, version 20061124. 2006. http://www.ukbiobank.ac. uk/docs/2006ConsentformA.pdf (accessed December 2007)

29 Palmer LJ: UK Biobank: bank on it. Lancet 2007;369:1980-1982.

30 Medical Research Council: Human tissue and biological samples for use in research: operational and ethical guidelines. 2001. http://www.mrc.ac.uk/Utilities/Documentrecord/index.htm?d=MRC002420 (accessed September 2008).

31 Wendler D: One-time general consent for research on biological samples. BMJ 2006;332: 544-547.

32 Hansson MG: For the safety and benefit of current and future patients. Pathobiology 2007;74:198-205.

33 Tumorbank Bern. http://www.tumorbank. unibe.ch (accessed December 2007).

34 Grotzer MA, Shalaby T, Poledna T, Swiss Pediatric Oncology Group (SPOG): Establishment of the Swiss Paediatric Oncology Group (SPOG) Tumour Bank. Schweiz Krebs Bull 2003;23:180-184.

35 Human Tissue Act. London, HMSO, 2004.

36 Coroners (Amendment) Rules: Statutory Instrument 2005 No. 420. London, HMSO, 2005.

37 Human Tissue (Scotland) Act. London, HMSO, 2006.

-38 Mavroforou A, Giannoukas A, Michalodimitrakis E: Consent for organ and tissue retention in British law in the light of the Human Tissue Act 2004. Med Law 2006;25:427-434.

-39 Ackerman MJ, Tester DJ, Driscoll DJ: Molecular autopsy of sudden unexplained death in the young. Am J Forensic Med Pathol 2001;22:105-111.

40 Wedekind H, Schulze-Bahr E, Debus V, Breithardt G, Brinkmann B, Bajanowski T: Cardiac arrhythmias and sudden death in infancy: implication for the medicolegal investigation. Int J Legal Med 2007;121:245257.

41 Knoppers BM, Joly Y, Simard J, Durocher F: The emergence of an ethical duty to disclose genetic research results: international perspectives. Eur J Hum Genet 2006;14:11701178.

42 Pullman D, Hodgkinson K: Genetic knowledge and moral responsibility: ambiguity at the interface of genetic research and clinical practice. Clin Genet 2006;69:199-203

43 Roberts LW, Nolte KB, Warner TD, McCarty T, Rosenbaum LS, Zumwalt R: Perceptions of the ethical acceptability of using medical examiner autopsies for research and education: a survey of forensic pathologists. Arch Pathol Lab Med 2000;124:1485-1495. 